\title{
An evaluation of selected oral health indicators and cariogenic bacteria titer in patients with Helicobacter pylori
}

\author{
Jakub Urban ${ }^{1, A-E}$, Rafał Koszowski2, E, F, Anna Płachetka ${ }^{3, A}$, Andrzej Wiczkowski ${ }^{4, E, F}$ \\ 1 Private Medical Practice, Bielsko-Biała, Poland \\ ${ }^{2}$ Oral Surgery Section, Department of Cranio-Maxillofacial and Oral Surgery, Medical University of Silesia, Katowice, Poland \\ ${ }^{3}$ Department of Animal Physiology and Ecotoxicology, University of Silesia, Katowice, Poland \\ ${ }^{4}$ Department of General Medical Biology, Medical University of Silesia, Katowice, Poland \\ A - research concept and design; B - collection and/or assembly of data; C - data analysis and interpretation; \\ $D$ - writing the article; $E$ - critical revision of the article; $F$ - final approval of article
}

\author{
Address for correspondence \\ Jakub Urban \\ E-mail: stomatologia.urban@gmail.com \\ Funding sources \\ None declared \\ Conflict of interest \\ None declared

\begin{abstract}
Acknowledgments
Approval for the study was obtained from the Ethics Committee of the Silesian Medical University (No KNW/0022/KB1/161/10//111, dated 20.09.2011). The laboratory tests were subsidized by the Department for Science and International Cooperation of the Medical University of Silesia (Contract No KNW-1-074/D/1/0).
\end{abstract}

Received on March 22, 2015

Revised on May 29, 2015

Accepted on February 24, 2016

\begin{abstract}
Background. Studies based on polymerase chain reaction (PCR) techniques indicate that Helicobacter pylori can be constantly or temporarily present in the oral cavity in virulent or non-virulent form. Streptococcus mutans exerts a strong inhibitory effect on H. pylori.
\end{abstract}

Objectives. The aim of the present study was to investigate the prevalence and virulence of $H$. pylori in the oral cavity and the correlation of these factors with oral health and cariogenic bacteria titer.

Material and methods. The study involved 108 adults who were positive in urease tests for H. pylori presence in the gastric mucosa. Group I consisted of 50 patients with positive saliva tests using PCR for the presence of $\mathrm{H}$. pylori DNA, while group II comprised 58 patients with negative tests. The research material consisted of saliva and dental plaque. To determine the density of $S$. mutans and Lactobacillus, commercially available $S$. mutans and $L B$ sets were used.

Results. H. pylori DNA was found in the oral cavities of $46 \%$ of the patients who had tested positive in urease tests for the presence of these bacteria in the stomach. Among those who tested positive for the presence of $\mathrm{H}$. pylori in the oral cavity, virulent strains were identified in $16 \%$ of the patients. Approximal plaque index (API) and bleeding on probing (BOP) were found to be significantly higher in patients with confirmed H. pylori in the oral cavity. This group also had a smaller number of $S$. mutans colonies.

Conclusions. H. pylori is found more often in patients with poor oral hygiene. Oral sanitation and hygiene instructions should be considered relevant as a complement to eradication therapy.

Key words: PCR, saliva, Lactobacillus, dental plaque, Streptococcus mutans

DOI

10.17219/acem/61907

\section{Copyright}

Copyright by Author(s)

This is an article distributed under the terms of the

Creative Commons Attribution Non-Commercial License

(http://creativecommons.org/licenses/by-nc-nd/4.0/) 
Helicobacter pylori is a Gram-negative spiral bacterium from the $\varepsilon$-proteobacteria family. The optimal temperature for the bacterium's existence ranges from $36-42^{\circ} \mathrm{C}$, at a $\mathrm{pH}$ of between 5 and 7 in microaerophilic conditions. $H$. pylori plays a significant role in the pathogenesis of gastric carcinoma and mucosa-associated lymphoid tissue (MALT) lymphomas. ${ }^{24}$

The bacterium is highly sensitive to acids, and protects itself from their influence with help of its mucus layer and the production of urease in large amounts. This enzyme, encoded by 7 ure genes, constitutes one of the major factors of pathogenic activity, hence the division into pathogenic urease-positive strains and nonpathogenic ureasenegative strains, which only occur in laboratory culture conditions. $^{25}$

Helicobacter pylori occurs in 3 forms: living spiral culture forms, which are virulent and infectious in character and cause inflammation in experimental animals; living spherical non-culture forms, which have less ability to colonize and cause infections in experimental animals; and residual degenerative forms of dying H. pylori. ${ }^{1}$

The incidence and prevalence of $H$. pylori infection in the human population is estimated at $50 \%$. In developing countries with low socio-economic conditions the rate is around $80-100 \%$, and in developed countries it is in the region of $20-40 \%$. Humans are considered the main carrier of this bacteria. Routes of transmission have been described based on oral-oral, fecal-oral and gastro-oral theories. ${ }^{2}$

Laboratory tests have shown that some strains of $H$. pylori have the ability to form biofilm in vitro. The formation of biofilm is associated with the binding of individual bacteria, which form microcolonies that grow in 3 dimensions. ${ }^{2}$ Biofilm is prevalent in the oral cavity, and spiral and spherical forms of $H$. pylori can be detected in dental plaque. ${ }^{1}$

The presence of $H$. pylori in the oral cavity has been confirmed by polymerase (PCR). ${ }^{3}$ In other studies $H$. pylori has been isolated from saliva, dental plaque and various pathological lesions in the oral cavity. ${ }^{4-6}$ The amounts of $H$. pylori genetic material found vary widely from study to study. For example, Song et al. isolated bacteria from $97 \%$ of dental plaque samples and $55 \%$ of saliva samples, whereas Cammarota et al. confirmed its presence in only $3.2 \%$ of dental plaque samples. ${ }^{7,8}$ There are some difficulties in comparing these results due to the use of different primers, PCR protocols and sampling techniques. Chamanrokh et al. suggested the potential occurrence of non-culture spherical forms in the oral cavity. ${ }^{9}$

Some studies indicate that the $H$. pylori strains isolated from the oral cavity differ from gastric strains, whereas other researchers have stated that identical strains are present in both the oral cavity and the stomach. ${ }^{7,10}$ In most cases, patients who tested positive for $H$. pylori in the oral cavity also had positive gastric biopsy results, but a large number of patients with gastric infections do not present co-infection in the oral cavity. ${ }^{11}$
H. pylori in the oral cavity may also interact with the components of its ecosystem. A study by Okuda et al. indicates that Porphyromonas gingivalis and Fusobacterium nucleatus interact with $H$. pylori strains. ${ }^{12}$

The bacterial component of the cariogenic process plays a critical role in the pathogenesis of changes. Streptococcus mutans and Lactobacillus acidophilus are currently considered to be the most cariogenic species of bacteria. $S$. mutans bacteria are the primary cariogenic colonizers. Their development and high titer may help to drive H. pylori out of its niches in the oral cavity, and when $H$. pylori numbers are low, ideal conditions for $S$. mutans colonization are present. In turn, Lactobacillus is a prominent member of the late cariogenic flora family with an unconfirmed impact on the $H$. pylori population. Investigating the tendency for S. mutans and Lactobacillus to interact with $H$. pylori may help to clarify the conditions that the bacteria need to exist in the oral cavity. This would help to ensure effective diagnoses and eradication therapy for H. pylori.

The aims of the study were to assess the presence and degree of virulence of $H$. pylori bacteria in the saliva and dental plaque of patients with positive urease results from a gastric biopsy; to evaluate selected indicators of oral health in patients with confirmed and unconfirmed $H$. pylori present in their saliva and dental plaque; and to determine the Streptococcus mutans and Lactobacillus bacteria index in the oral cavities of patients with confirmed and unconfirmed H. pylori in their saliva and dental plaque. ${ }^{1-3}$

\section{Material and methods}

The study was conducted on adult patients (both sexes) at the Endoscopy Unit of the Central Clinical Hospital in Katowice, Poland, which is part of the Department of Gastroenterology and Hepatology of the Medical University of Silesia in Katowice. As part of the gastroenterological diagnostic process, patients underwent a gastroscopy that included an urease test. A total of 108 patients with positive $H$. pylori urease tests in the gastric mucosa qualified for the next stage of the study. The participants provided written consent for the study and had to meet strict inclusion criteria for the study groups, as follows:

- a positive urease test result during a gastroscopy;

- aged over 18;

- no severe general diseases affecting their oral health (e.g., neoplastic diseases, systemic diseases, untreated diabetes);

- no inflammatory conditions in their oral mucosa that significantly affected the environment (erosive lesions, ulcerations, RAS syndrome, fungal infections, etc.);

- a minimum of 24 teeth in the oral cavity.

Patients who did not meet the above criteria, as well as pregnant women, people wearing removable partial 
dentures, patients treated with bismuth compounds and/ or antibiotics in the previous 2 months and patients who had undergone previous eradication therapy or immunosuppressive therapy were excluded from the study. The age of the 108 subjects accepted ranged from 18 to 68 years, with an average age of 42 years. Women made up $60.2 \%$ of the study group.

Patient interviews and physical examinations were conducted in separate rooms. The prepared questionnaires were filled in with data obtained from the patients. Selected dental indicators - namely the Simplified Oral Hygiene Index (OHI-S, devised by Greene and Vermillion), approximal plaque index (API) and bleeding on probing (BOP) were determined. The API is used to evaluate oral hygiene by assessing the presence of dental plaque in interdental spaces. BOP is used to evaluate the degree of bleeding from periodontal pockets and rapidly estimate the severity of a patient's gingivitis. In a simplified procedure assessments are made of the palatal surfaces and linguistic quadrants 1 and 3 and 2 and 4 of the vestibular dentition quadrant.

\section{Procedures for sampling and preserving the genetic material}

A total of $3 \mathrm{~mL}$ of stimulated saliva was collected from each patient along with a small quantity of dental plaque from the lingual side or palatal surface of a molar. Each patient, in a fasting state, received a paraffin cube and a sterile plastic vial. By holding the paraffin cube in the oral cavity and chewing it gently the patient was able to deposit stimulated saliva in the opened vial. Once $3 \mathrm{~mL}$ of saliva (the level marked on the previously prepared vial) was obtained, plaque was collected using a disposable probe and deposited in the vial with the saliva. The vial with the study material was secured with a factory default plastic cap and mounted in a rack in a portable refrigerator at about $5^{\circ} \mathrm{C}$. Then a non-invasive bacteriological examination was performed to determine the bacteriological index of $S$. mutans and Lactobacillus, using ready-to-use Dentocult SM and LB kits (Orion Diagnostica, Espoo, Finland).

The kits were placed in an incubator set at $37^{\circ} \mathrm{C}$. The result for $S$. mutans was read after 3 days of incubation, whereas the Lactobacillus result was recorded after 4 days. The quantitative results for the bacterial colonies were evaluated with the Dentocult SM and LB kits. They were determined in colony-forming units $/ \mathrm{mL}(\mathrm{CFU} / \mathrm{mL})$. In the case of $S$. mutans these values were additionally ranked by the manufacturer according to classes. Lactobacillus bacteria were evaluated quantitatively using the ready-to-use interpretative keys accompanying the Dentocult LB kits, which assessed them as $<10^{3}, 10^{3}, 10^{4}, 10^{5}$ or $10^{6} \mathrm{CFU} / \mathrm{mL}$.

The study material in the form of collected saliva and dental plaque was properly secured and immediately transported to the Department of General Medical Biology at the Medical University of Silesia in Katowice to determine the presence of $H$. pylori genetic material using
PCR. On the basis of the results, the study participants were divided into 2 groups: group I, which consisted of 50 subjects (including 29 [26.9\%] women) with positive PCR saliva test results for the presence of $H$. pylori DNA, and group II, consisting of 58 subjects (including 36 [33.3\%] women) with negative results.

The gastric biopsies were collected in $1.5 \mathrm{~mL}$ tubes containing $200 \mathrm{~mL}$ of RNAlater nucleic acid stabilizer (Sigma-Aldrich, Hamburg, Germany). They were properly secured and then transported to the laboratory, where they were stored at $-20^{\circ} \mathrm{C}$ until the beginning of the analysis. They served as positive control standards in the PCR process.

The vials containing $3 \mathrm{~mL}$ of saliva with a small amount of dental plaque suspended in it were sent to a laboratory, where they were stored at $-20^{\circ} \mathrm{C}$ until the beginning of the analysis.

\section{Genomic DNA extraction}

The dental plaque was scraped from the patient's teeth and put in $3 \mathrm{~mL}$ sterilized tubes. The samples were frozen at $-20^{\circ} \mathrm{C}$ before being transported to the laboratory. The DNA was extracted using a QIAamp ${ }^{\circledR}$ DNA Mini Kit (Qiagen, Germany) in accordance with the protocol provided in the manual kit (QIAamp DNA Mini and Blood Mini Handbook 04/2010).

\section{PCR}

The PCR amplification procedure was carried out with a Mastercycler Personal PCR thermal cycler (Eppendorf, Hamburg, Germany). The PCR mix included the following: $12.5 \mu \mathrm{L}$ of PCR Master Mix, including a ready-touse solution containing “Taq"DNA Polymerase, dNTPs, $\mathrm{MgCl}_{2}$ and reaction buffers (Promega, Madison, USA); $10 \mathrm{pM}$ of each primer (forward and reverse); and $2.5 \mu \mathrm{M}$ of each dNTP. Approximately $400 \mathrm{ng}$ of the isolated DNA was used as a template. Nuclease free water was added to make up the reaction volume $(25 \mu \mathrm{L})$. The DNA extracted from $H$. pylori obtained from the gastric biopsies with positive urease test results served as a positive control. The primer sets used in the PCR process for this study are presented in Table 1.

The PCR amplification results were viewed using 1.5\% agarose gel with GelStar Stain (Lonza, Visp, Switzerland) under ultra-violet light and photographed.

The full text of the laboratory procedures that were used in this study is available on request via e-mail.

\section{Statistical analysis}

The statistical analysis of the results was performed using STATISTICA software, v. 10 (StatSoft, Tulsa, USA). Median values, mean values and standard devia- 
Table 1. Primer sequences with PCR product

\begin{tabular}{|c|c|c|c|c|c|}
\hline Primers & Sequence of primers $5^{\prime}-3^{\prime}$ & Gene & $\begin{array}{c}\text { Annealing } \\
\text { temperatures } \\
\left({ }^{\circ} \mathrm{C}\right)\end{array}$ & Product size (bp) & Source \\
\hline HPU1/HPU2 & $\begin{array}{l}\text { CGTGCATACCCCTATTGAGG } \\
\text { CACGCTCTTTAGCTCTGTG }\end{array}$ & Urease A & $62-60-58-56-54$ & 380 & $\begin{array}{l}\text { Song et al. } 1999 \\
\text { with modifications }\end{array}$ \\
\hline HP1/HP2 & $\begin{array}{l}\text { CGTTAGCTGCATTACTAGAGAG } \\
\text { CATTACTGACGCTGATTGCGC }\end{array}$ & $16 s r$ RNA & $66-64-62-60-58$ & 110 & $\begin{array}{l}\text { Song et al. } 1999 \\
\text { with modifications }\end{array}$ \\
\hline HPOS/HPOAS & $\begin{array}{l}\text { GTGTGGGAGAGGTAGGTGGA } \\
\text { TGCGTTAGCTGCATTACTGG }\end{array}$ & $16 s r$ RNA & $62-60-58-56-54$ & 216 & Chaudhry et al. 2001 \\
\hline EHC-U/EHC-L & $\begin{array}{l}\text { CCCTCACGCCATCAGTCCCAAAAA } \\
\text { AAGAAGTCAAAAACGCCCCAAAAC }\end{array}$ & $\begin{array}{l}860 \text { bp DNA } \\
\text { region }\end{array}$ & 58 & 417 & Song et al. 1999 \\
\hline ET-5U/ET-5L* & $\begin{array}{l}\text { GCCAAATCATAAGTCCGAAGAA' } \\
\text { TGAGACTTTCCTAGAAGCGGTGTT }\end{array}$ & $\begin{array}{l}860 \text { bp DNA } \\
\text { region }\end{array}$ & 58 & 230 & Song et al. 1999 \\
\hline CagA & $\begin{array}{l}\text { GATAACAGGCAAGCTTTTGAGG } \\
\text { CTGCAAAAGATTGTTTGGCAGA' }\end{array}$ & CagA & $62-60-58-56-54$ & 349 & Yamaoka et al. 1999 \\
\hline
\end{tabular}

*ET-5U/ET-5L - primers for nested PCR, which are directed to the 417-bp productof primers EHC-U/EHC-L.

tions were calculated. The statistical hypotheses based on these results were verified using the non-parametric Mann-Whitney $U$ test. In addition, the test $\chi^{2}$ of independence was used to analyze differences between the data measured on a weak measurement scale. The decision to use the Mann-Whitney test was dictated by several cases of deviations in the distribution of the characteristics compared to normal distribution, which was checked using the Shapiro-Wilk test. To verify the statistical hypotheses, the following levels of statistical significance were adopted: $\mathrm{p}>0.05$ - no significance; $\mathrm{p}<0.05$ - statistical significance; $\mathrm{p}<0.01$ - high statistical significance.

Approval for the study was obtained from the Ethics Committee of the Silesian Medical University (No. KNW/0022/KB1/161/10/I/11, dated 20.09.2011). The laboratory tests were subsidized by the Department for Science and International Cooperation of the Medical University of Silesia (Contract No. KNW-1-074/D/1/0).

\section{Results}

Of the 108 subjects known to have $H$. pylori present in the stomach, molecular testing showed that 50 had H. pylori DNA present in their saliva samples and in the plaque suspended in the saliva (group I). In 58 patients genetic tests revealed no $H$. pylori DNA present in the oral cavity despite confirmed infection of the gastric mucosa (group II). Therefore, the presence of $H$. pylori bacteria in the oral cavity was detected in $46 \%$ of the patients with urease-positive bacteria detected in the stomach.

\section{Data tables for oral health indicators}

The mean OHI-S value, API and BOP percentages were higher in group I than in group II, and the Mann-Whitney U test showed that these differences were statistically significant in the cases of the API and BOP (API: $p=0.0028$, BOP: $\mathrm{p}=0.0013$ ). The difference between the two groups' OHI-S values was not statistically significant $(\mathrm{p}=0.4324)$.

\section{Test results of Streptococcus mutans and Lactobacillus cultures}

The statistical analysis showed significant differences in the number of $S$. mutans bacterial colonies in the 2 study groups. A higher number of bacterial colonies was observed in study group II compared to group I ( $\mathrm{p}=0.0065)$. The reverse trend was observed in the case of Lactobacillus cultures: The number of colonies of this type was higher in group I than in group II; however, the difference was not statistically significant $(\mathrm{p}=0.3363)$.

Of the 50 patients who tested positive for the presence of $H$. pylori in their oral cavities (group I), virulent strains $(\mathrm{cag} \mathrm{A}+)$ were confirmed in 8 cases, which represents $16 \%$ of the group. Due to the small size of the subgroup known to have the virulent strain, it was difficult to reliably assess the differences in average oral health and cariogenic bacteria values, both in the case of the 2 subgroups, as well as with respect to group I as a whole. However, no statistically significant correlations were present, either in the subgroup with known virulence or in the subgroup with non-virulent strains. 
One fact observed was that patients with virulent strains of $H$. pylori detected in the oral cavity did not use antibacterial mouthwashes ( $0 / 8$ patients). The percentage of patients with nonvirulent strains of $H$. pylori in the oral cavity who used mouthwashes was $31 \%$ (13/42 patients). Among patients in group II, who tested negative in the PCR examination for $H$. pylori in their oral cavities, 41\% used mouthwashes (24/58 patients).

In patients with virulent strains of the bacteria more frequently suffered from active gastrointestinal diseases: $87 \%$ of the patients from the virulent subgroup had at least one such disorder. In the subgroup with non-virulent strains, the percentage of patients with diseases of this type was $62 \%$, as compared with $68 \%$ of people with no $H$. pylori present in the oral cavity. Due to the small size of the subgroup with virulent strains (cagA+) these results were not statistically significant.

\section{Discussion}

The research conducted by the authors of the present study consisted in isolating $H$. pylori DNA from the saliva of patients who had tested positive for the presence of this bacteria in their gastric mucosa during a gastroscopy. The presence of $H$. pylori in the oral cavity has been the subject of numerous studies and has aroused controversy. Its presence in this environment in residual or transient form is a fact. On the other hand, the frequency and amount of bacteria in the oral cavity has not been fully established. To date, only a few mechanisms of interaction have been shown to exist between different bacteria, and this can help to improve our understanding of the occurrence and role of $H$. pylori in pathologies of the oral cavity. Its presence in plaque is highest in the area around the molars and lowest in the region of the premolars and incisors. ${ }^{13}$ This fact may be due to oxygen exposure, which increases in the mesial direction, and this in turn can lead to the formation of distal niches.

Many different methods have been developed to detect H. pylori in the oral cavity. The PCR method, however, is the most accurate and most suitable for research purposes. The most sensitive method for testing saliva involves the use of EHC-U/EHC-L primers. The only disadvantages of molecular methods are that they are expensive and are technically more difficult compared to breeding, histological methods and rapid urease tests. The $16 \mathrm{~S}$ rRNA gene marker has been shown to be the most accurate method. ${ }^{14}$

In the present study, the detection rate of $H$. pylori in the oral cavity of patients with urease-positive bacteria in their stomach was $46 \%$. This is comparable to the findings of a study by Gebara et al., in which, out of the 100 patients who tested positive for $H$. pylori in gastric mucosa, positive results for the presence of the bacteria in the oral cavity were noted in $43.3 \%$ of cases. ${ }^{15}$ Accord- ing to other researchers, PCR DNA analysis revealed H. pylori in the oral cavity in $3-89 \%$ of cases. ${ }^{4,7,8,14,16}$ Such disparate results may be due to different procedures employed for sampling, or a consequence of the primers used. This is because microorganisms similar in shape as well as other urease-producing bacteria may in fact be present in complex biofilm. Dental plaque has been called "a reservoir for genotypes", where horizontal gene transfer can take place between the bacteria that reside in the biofilm. ${ }^{17,18}$ The genotypic variability of this bacteria manifests itself in the presence of point mutations and changes in the gene sequence. This may lead to both false positive and false negative results if the PCR test is limited to determining a single gene. The present study therefore identified 4 different genes, namely: $16 \mathrm{~S}$ rRNA (two kinds of primers), UreA, 860bp DNA region (2 types of primers) and cagA. Recognition of a combination of at least 2 different, simultaneously occurring genes was regarded as a positive result. ${ }^{18}$ Individually marked genes were analyzed for the sensitivity and specificity of the primer. A 16S rRNA region that amplifies the 106bp fragment and the region from human leukocytes presents low specificity. This may consequently lead to false positive results. The urease gene may not be present in all strains of $H$. pylori, which means there is a chance of obtaining false negative results. Other species of bacteria that secrete urease in the plaque, such as Streptococci, Actinomyces or Haemophilus spp, can cause false positives. ${ }^{18,19}$

The research team of Silva et al. demonstrated a correlation between the colonization of supragingival plaque and oral health parameters - specifically, between the percentage of the surface covered with dental plaque and the bleeding rates of periodontal pockets. ${ }^{16}$ Patients with higher values of these 2 indicators were likely to report the presence of $H$. pylori in their oral cavities. The authors also demonstrated a 98\% DNA sequence identity in gastric, saliva and plaque bacteria. The present study shows a statistically significant difference between the 2 study groups in terms of the amount of interdental plaque (API) and bleeding from periodontal pockets (BOP): Higher values of both indices were observed among the patients with H. pylori present in the oral cavity.

The present study, based on a simplified OHI-S index, showed that $H$. pylori was more likely to be detected in patients with higher levels of this index, despite the lack of any statistical significance. When analyzing mean values and extremes of the index, the simplified model should be abandoned so that the total index for all teeth can be measured to ensure greater research accuracy. Most of the tooth surfaces marked in a simplified indicator test are easily accessible for hygiene procedures, while other areas may remain uncleaned. This fact may have an impact on the total index.

Considering all 3 of the oral hygiene indices used in this study - the OHI-S, API and BOP - it can be concluded that a patient's oral hygiene status affects the diagnosis 
and treatment of $H$. pylori infections. Jia et al. emphasize the importance of dental plaque as a temporary reservoir of bacteria and show that long-term professional management reduces re-infection of the stomach following eradication treatment. ${ }^{19,20}$ The failure of triple eradication therapy for treating $H$. pylori in the oral cavity is a consequence of a failure to achieve an effective concentration of antibiotics in the saliva and dental plaque. ${ }^{19,20}$ Okuda et al. and Andersen et al. demonstrated that strains of $P$. gingivalis and F. nucleatum strongly co-agregate with H. pylori strains. ${ }^{1,12}$ Okuda et al. also observed that Streptococcus oralis, Streptococcus mitis, Streptococcus mutans Streptococcus, Streptococcus sorbinus, Actinomyces naeslundi, Prevotella intermedia and Prevotella nigrescens produce bacteriocin-like, anti-H. pylori ihibitor proteins. ${ }^{12}$ In patients with appropriate oral hygiene, low or even no trace amounts of $H$. pylori bacteria may be present in the oral cavity. This is explained by the fact that the the bacterium is driven out by early colonizers of the oral cavity. Gebara et al. suggest that a high percentage of positive $H$. pylori results in the oral cavity is associated with poor oral hygiene: As noted earlier, among their patients who tested positive for the presence of $H$. pylori in the gastric mucosa, the same bacteria was present in $43.3 \%$ of patients whose oral hygiene was clearly worse than the rest of the study group. ${ }^{15}$ Analyzing the data, it must be assumed that in the $H$. pylori positive group of patients in the above studies there was a predominance of late colonizers in the oral cavity, or cariogenic bacteria, i.e., microorganisms of the Lactobacillus group. ${ }^{12,15}$ The present study indicates a trend towards a higher incidence of bacterial colonies of Lactobacillus in patients with $H$. pylori in the oral cavity than in those in whom this bacteria was not present in the oral cavity. However, the difference was not statistically significant.

The authors observed that none of the people in the subgroup with virulent strains of $H$. pylori in the oral cavity used antibacterial mouthwashes, while $31 \%$ of the people diagnosed with non-virulent strains used mouthwashes. The percentage of mouthwash users in group II, where no $H$. pylori was detected in the oral cavity, was $41 \%$. The absence of $H$. pylori in patients using mouthwashes most probably does not indicate the direct impact of mouthwashes on this bacterium, but rather on the biofilm as a whole. This causes subsequent quantitative and qualitative changes in plaque mass in relation to the proportion of Lactobacillus and Streptococcus strains.

Various studies have reported a negative correlation between the presence of $H$. pylori and the number of S. mutans colonies. ${ }^{12}$ Likewise, the present study showed a statistically significant increase in the density of $S$. $m u$ tans bacterial colonies in patients without $H$. pylori.

Two research teams, Assumpção et al. and Momtaz, were able to show the presence of $H$. pylori strains with virulent factors in the oral environment by determining factors of bacterial pathogenicity in molecular stud- ies. ${ }^{21,22}$ Positive genotype babA2, cagA and vacA bacterial strains involve a higher risk of metaplastic changes developing when compared to gene-free strains. Hacker and Kaper introduced the concept of a pathogenicity Island (PAI). This theory defines a DNA segment with a specific nucleotide composition, at the end of which the cagA gene is located, which is responsible for encoding a highly immunogenic cagA protein. ${ }^{22,23}$ It is found in $60-80 \%$ of $H$. pylori strains, and its presence is associated with the production of the vacuolating cytotoxin (vacA). The $H$. pylori cagA genotype and vacAs1m1 are associated with an increased risk of adenocarcinoma of the stomach. Assumpção et al. found a genotypic similarity (cagA and vacA) between $H p$ bacterial isolates in the stomach and the oral cavity. ${ }^{21}$ According to those researchers, the $H$. pylori in plaque is associated with acute gastrointestinal disorders, such as gastroesophageal reflux, which can lead to the virulent strains vacAs1m1+ and cagA+ colonizing the mouth. The present study indicates that the vast majority of people $(87.5 \%)$ with virulent $H$. pylori strains in the oral cavity suffer either from active stomach ulcers (5/8 patients) of varying degrees of severity, or from gastroesophageal reflux disease (4/8 patients). Half of the respondents had undergone eradication therapies between 2 and 5 years previously and were currently diagnosed with a reinfection.

Both the research conducted by the authors of this study and an analysis of the literature on the subject indicate that every individual undergoing eradication therapy should be provided with dental care so that they can receive dental treatment and instructions in oral hygiene.

\section{Summary and conclusions}

$H$. pylori was observed in the oral cavity of $46 \%$ of the patients that had a positive urease test in a biopsy of the gastric mucosa. The presence of virulent strains was observed in $16 \%$ of the patients with confirmed $H$. pylori in the oral cavity.

Higher BOP, OHI-S and API values, and thus poor hygiene and gum inflammation, were noted in patients that had positive urease tests in biopsies of the gastric mucosa as well as $H$. pylori confirmed in the oral cavity.

Fewer colonies of Streptococcus mutans were found in patients with confirmed $H$. pylori in the gastric mucosa and the oral cavity than in patients without H. pylori confirmed in the oral cavity.

A higher number of Lactobacillus colonies were observed in patients with $H$. pylori present in the oral cavity than in patients with no $H$. pylori in the oral cavity. However, the correlation was not statistically significant.

Every individual who undergoes eradication therapy should receive dental care in order to check the state of their oral hygiene and eliminate the potential risk of reinfection from oral niches. 


\section{References}

1. Andersen LP, Rasmussen L. Helicobacter pylori - coccoid forms and biofilm formation. FEMS Immunol Med Microbiol. 2009;56:112-115.

2. Cellini L, Grande R, Di Campli E, Di Bartolomeo S, et al. Characterization of an Helicobacter pylori environmental strain. J Appl Microbiol. 2008;105:761-769.

3. Bharath TS, Reddy MS, Dhanapal R, Raj Kumar NG, Neeladri Raju $\mathrm{P}$, Saraswathi T. Molecular detection and corelation of Helicobacter pylori in dental plaque and gastric biopsies of dyspeptic patients. J Oral and Maxillofacial Pathol. 2014;18(1):19-24.

4. Al Sayed A, Anand PS, Kamath KP, Patil S, Preethanath RS, and Sukumaran A. Oral cavity as an extragastric reservoir of Helicobacter pylori. ISRN Gastroenterol. 2014; Article ID 261369, 16 pages.

5. Anand PS, Kamath KP, Anil S. Role of dental plaque, saliva and periodontal disease in Helicobacter pylori infection. World J Gastroenterol. 2014;20(19): 5639-5653.

6. Irani, S, Monsef Esfahani, A, Bidari Zerehpoush F. Detection of Helicobacter pylori in oral lesions. J Dent Res Dent Clin Dent Prosp. 2013;7(4):230-237.

7. Song Q, Haller B, Schmid RM, Adler G, Bode G. Helicobacter pylori in dental plaque. A comparison of different PCR primer sets. Dig Dis Sci. 1999;44:479-484.

8. Cammarota G, Tursi A, Montalto M. Role of dental plaque in the transmission of Helicobacter pylori infection. J Clin Gastroenterol. 1996;22:174-177.

9. Chamanrokh P, Shahhosseiny MH, Mazaheri Assadi M, Nejadsattari T, Esmaili D. Three tests used to identify non-culturable form of Helicobacter pylori in water samples. Jundishapur J Microbiol. 2015;8(4):e16811.

10. Adler I, Muiño A, Aguas S, et al. Helicobacter pylori and oral pathology: Relationship with the gastric infection. World J Gastroenterol. 2014;20(29):9922-9935.

11. Madinier IM, Fosse TM, Monteil RA. Oral carriage of Helicobacter pylori: A review. J Periodontol. 1997;68:2-6.

12. Okuda K, Kimizuka R, Katakura A, Nakagawa T, Ishihara K. Ecological an immunopathological implications of oral bacteria in Helicobacter pylori - infected disease. J Periodontol. 2003;74:123-128.
13. Song Q, Lange T, Spahr A, Adler G, Bode G. Characteristic distribution pattern of Helicobacter pylori in dental plaque and detected with nested PCR. J Med Microbiol. 2000;49:349-353.

14. Bielański W. Diagnostyka zakażeń Helicobacter pylori. Medycyna po Dyplomie (Wydanie Specjalne). 2006;6:44-49.

15. Gebara EC, Pannuti C, Faria CM. Prevalence of Helicobacter pylori detected by polymerase chain reaction in the oral cavity of periodontitis patients. Oral Microbiol Immunol. 2004;19:277-280.

16. Silva DG, Stevens RH, Macedo JM, et al. Presence of Helicobacter pylori in supragingival dental plaque of individuals with periodontal disease and upper gastric diseases. Arch Oral Biol. 2010;55:896-901.

17. Shahnawaz K, Tabassum H, Shahnawaz K. Association of Helicobacter pylori infection in dental plaque and gastric infections. Int J Sci Stud. 2015;3(2):64-67.

18. Sugimoto M, Wu JY, Abudayyeh $\mathrm{S}$, et al. Unreliability of results of PCR detection of Helicobacter pylori in clinical or environmental samples. J Clin Microbiol. 2009;47:738-742.

19. Jia $\mathrm{CL}$, Jiang GS, $\mathrm{Li} \mathrm{CH}$, Li CR. Effect of dental plaque control on infection of Helicobacter pylori in Gastric Mucosa. J Periodontol. 2009;80:1606-1609.

20. Kignel S, de Almeida Pina F, Andre EA, Alves Mayer MP, Birman EG. Occurrence of Helicobacter pylori in dental plaque and saliva of dyspeptic patients. Oral Dis. 2005;11:17-21.

21. Assumpção MB, Martins LC, Melo Barbosa HP, Barile KA, de Almeida SS, Assumpção PP. Helicobacter pylori in dental plaque and stomach of patients from Northern Brazil. World J Gastroenterol. 2010;28(16):3033-3039.

22. Momtaz H, Souod N, Dabiri H, Sarshar M. Study of Helicobacter pylori genotype status in saliva, dental plaques, stool and gastric biopsy samples. World J Gastroenterol. 2012;7(18):2105-2111.

23. Vannini A, Roncarati D, Spinsanti M, Scarlato V, Danielli A. In depth analysis of the Helicobacter pylori cag pathogenicity island transcriptional responses. PLoS One. 2014;9(6):e98416.

24. Kandulski A, Selgrad M, Malfertheiner S. Helicobacter pylori infection: A clinical overview. Digest Liver Dis. 2008;20:619-626.

25. Amieva MR, El-Omar EM. Host-bacterial interactions in Helicobacter pylori infection. Gastroenterol. 2008;134:306-323. 